\title{
PEMETAAN POTENSI EKOWISATA DI DESA TANJUNG BELIT DAN DESA LUBUK BIGAU KECAMATAN KAMPAR KIRI HULU KABUPATEN KAMPAR PROVINSI RIAU
}

\author{
Abdullah Rinaldi Zen ${ }^{1}$, Emy Sadjati ${ }^{2}$, Muhammad Ikhwan ${ }^{2}$ \\ ${ }^{1}$ Mahasiswa Fakultas Kehutanan Universitas Lancang Kuning \\ ${ }^{2}$ Staff Pengajar Fakultas Kehutanan Universitas Lancang Kuning \\ Email: arizcameroon@gmail.com, emy_mnhunilak@yahoo.co.id,dan mmighwan@yahoo.com
}

The Village of Tanjung Belit and Lubuk Bigau Village Kampar Kiri Hulu Sub-district Kampar Regency has many tourism potentials that can improve the economy and regional income. This research utilizes geographic information system technology (GIS) to map potential natural tourism area because it is considered more effective and efficient. Geographic Information System is one of information system development that combine information system with geography, which is widely used to make planning, analysis, and decision making. The research entitled "Potency Mapping Of Ekowisata In Tanjung Belit Village And Village Power Of Bigau Kampar Kampar Kuli Hulu Kampar Kampar Provinsi Riau", with the formulation of problem how effort in inventory and mengetekan natural tourism potential object. The purpose of this research is to inventory and map the potential objects of nature tourism. This research use survey method or direct visit to research object. Sources of data used are primary and secondary data obtained from the observation and taking coordinates and tracks in the field, as well as the map of the earth Indonesia indonesia subdistrict kampar left upstream. Data were analyzed using descriptive analysis method. The theoretical basis used is tally sheet guidance of object analysis and natural attraction of Directorate General PHKA 2003 and also software ArcGis 10.1. Based on data analysis, the result of this research is information of 5 potential objects of natural tourism, namely: (1) waterfall cotton stem $\pm 150 \mathrm{~m}$, (2) cotton stem waterfall $\pm 50 \mathrm{~m}$, (3) waterfall stone wall 1 , (4) rock waterfall wall 2, and (5) water surfing. As well as a potential map that contains information about potential objects of natural tourism.

Keywords: Tourism Potential, Tanjung Belit Village, Lubuk Bigau Village, ArcGis.

\section{PENDAHULUAN}

Menurut data statistik Kementerian Lingkungan Hidup dan Kehutanan pada tahun 2015 Provinsi Riau merupakan salah satu provinsi yang memiliki luas hutan konservasi dan hutan lindung seluas $867.435 \mathrm{Ha}$. Dari luasan hutan lindung dan hutan konservasi yang ada di Provinsi Riau terdapat beberapa kawasan yang memiliki potensi untuk dijadikan sektor pariwisata.

World Tourism Organization (WTO) pada 1995 menunjukkan bahwa telah muncul perkembangan pariwisata alternatif yang dipandang lebih menghargai lingkungan dan juga kebudayaan masyarakat lokal. Kenyataan tersebut kini memicu 
kesadaran pembangunan pariwisata yang berwawasan lingkungan sebagai "alternative tourism" (Raharjana, 2012).

Kecamatan Kampar Kiri Hulu Kabupaten Kampar khususnya Desa Tanjung Belit dan Desa Lubuk Bigau mempunyai banyak potensi pariwisata yang dapat meningkatkan ekonomi dan pendapatan daerah. Adapun potensi pariwisata yang terdapat di Kecamatan Kampar Kiri Hulu Kabupaten Kampar menurut Dinas Pariwisata dan Kebudayaan Kabupaten Kampar yaitu: (1) Obyek wisata budaya (2) Obyek wisata alam. Untuk meningkatkan peran pariwisata sangat terkait antara barang yang berupa obyek wisata itu sendiri dengan sarana dan prasarana yang mendukung terkait dalam industri pariwisata.

Usaha mengembangkan suatu daerah pariwisata harus memperhatikan berbagai faktor yang berpengaruh terhadap keberadaan suatu daerah tujuan wisata. Faktor-faktor ini terkait lima unsur pokok yang harus ada dalam suatu daerah tujuan wisata yang meliputi obyek dan daya tarik wisata, prasarana wisata, tata laksana atau infrastruktur, kondisi masyarakat serta lingkungannya.
Sistem Informasi Geografis (SIG) merupakan salah satu pengembangan sistem informasi yang menggabungkan antara sistem informasi dengan ilmu geografi, yang saat ini banyak digunakan untuk membuat perencanaan, analisis, dan juga pembuatan keputusan, oleh karena itu peneliti bermaksud menggunakan teknologi sistem informasi geografis (SIG) untuk memetakan kawasan potensial wisata alam karena dinilai lebih efektif dan efisien dengan menggunakan perangkat lunak yang ada, terutama untuk wilayah Kecamatan Kampar Kiri Hulu yang diketahui memiliki banyak potensi wisata alam yang masih belum dikelola dengan baik dikarenakan masih kurangnya informasi untuk para wisatawan dan juga untuk pemerintah sebagai pengelola.

\section{METODE PENELITIAN}

Lokasi penelitian ini berada di Desa Tanjung Belit dan Desa Lubuk Bigau Kecamatan Kampar Kiri Hulu Kabupaten Kampar, Provinsi Riau. Penelitian ini dilakukan selama 4 bulan dengan pengambilan data di lapangan selama dua bulan yaitu bulan Mei sampai dengan bulan Juni 2017. 


\section{HASIL DAN PEMBAHASAN}

\section{Nama Obyek Potensial Wisata Alam}

Dari 2 desa yang telah diobservasi diperoleh 5 obyek potensial wisata alam yang berupa air terjun. Adapun nama dan data titik koordinat lokasi yang telah di observasi dapat dilihat dari tabel 1 dibawah ini

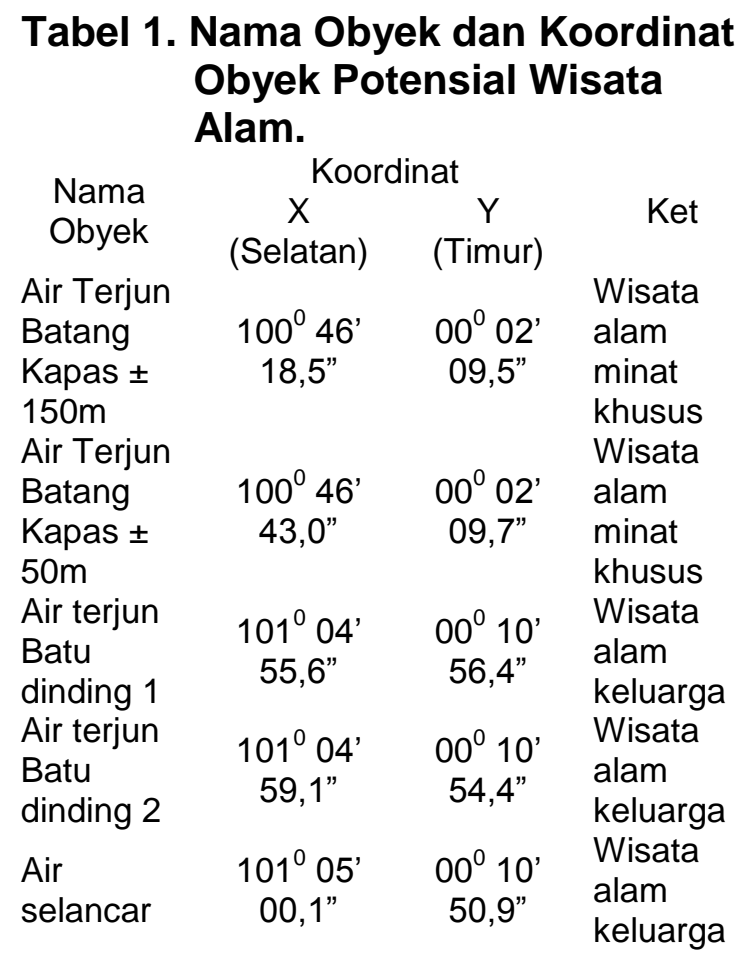

Sumber: Hasil Olahan Data Primer 2017

\section{Nilai Obyek Potensial Wisata Alam Menurut ADO-ODTWA}

Setelah melakukan observasi lapangan terhadap obyek potensial wisata alam, dilakukan juga penilaian dengan pangamatan yang mengacu kepada analisis Obyek dan Daya Tarik Wisata Alam (Direktorat Jenderal Perlindungan Hutan dan Konservasi
Alam tahun 2003) terhadap 5 obyek potensial wisata alam yang telah di kunjungi. Adapun jumlah skor dari penilaian analisis ODTWA dapat dilihat dari tabel 3 berikut.

Tabel 2. Nilai Obyek Potensial Wisata Alam Berdasarkan ADO-ODTWA

\begin{tabular}{|c|c|c|c|c|c|c|c|}
\hline Nuna Otyak & $\begin{array}{c}\text { DegaTrk } \\
\text { Whas }\end{array}$ & Muchilits & $\begin{array}{l}\text { Konfii } \\
\text { Lindingin }\end{array}$ & Ahrovini & $\begin{array}{l}\text { Sirma- } \\
\text { Prosana }\end{array}$ & Air & Totel \\
\hline $\begin{array}{l}\text { Air Taja Butas } \\
\text { Kagas = } 15 \text { ta }\end{array}$ & 90 & 175 & 175 & 6 & 90 & 900 & 2390 \\
\hline $\begin{array}{l}\text { Air Tajom Butas } \\
\text { Kepas }+56 a\end{array}$ & 1080 & 225 & 175 & $\omega$ & 90 & 900 & 2470 \\
\hline $\begin{array}{l}\text { Ar Truja Batr } \\
\text { Dinfing } 1\end{array}$ & 1050 & 375 & 25 & $\theta$ & 120 & 170 & 270 \\
\hline $\begin{array}{l}\text { Air Tajua Bin } \\
\text { Dinfing } 2\end{array}$ & 1050 & 375 & 235 & 60 & 120 & no & 270 \\
\hline Arr Stlocal & 1086 & 375 & 225 & 60 & 120 & 870 & 2700 \\
\hline
\end{tabular}

Setelah dilakukan penilaian pada obyek potensial yang telah didapat maka dilakukan pembagian interval nilai terhadap setiap unsur yang dinilai pada masing-masing obyek potensial wisata alam yang telah diinventarisasi. Dari 5 obyek potensial wisata alam yang telah diinventarisasi memiliki interval nilai untuk unsur daya tarik wisata sebagai berikut:

\section{Unsur Daya Tarik Wisata}

Interval skor yang didapat dari unsur daya tarik wisata dapat dilihat dari tabel berikut ini: 


\section{Tabel 3. Interval Skor Unsur Daya Tarik Wisata}

$\begin{array}{ccccccccc}\text { No. } & \text { Kategori } & \text { Interval } & \begin{array}{c}\text { Air Terjun } \\ \text { Batang Kapas Batang Kapas }\end{array} & \begin{array}{c}\text { Air Terjun } \\ \text { Batu }\end{array} & \begin{array}{c}\text { Air Terjun } \\ \text { Bir Terjun }\end{array} & \text { Air } \\ & & & \mathbf{1 5 0} \mathbf{~} & \mathbf{5 0 ~} \mathbf{~ m} & \text { Dinding 1 } & \text { Dinding 2 } & \text { Selancar } \\ 1 & \text { Tinggi } & 982-1260 & \text { Tinggi } & \text { Tinggi } & \text { Tinggi } & \text { Tinggi } & \text { Tinggi } \\ 2 & \text { Sedang } & 701-981 & 990 & 1020 & 1050 & 1050 & 1050 \\ 3 & \text { Rendah } & 420-700 & & & & & \end{array}$

Sumber: Hasil Olahan Data Primer 2017

Dari tabel diatas didapati bahwa 5 obyek potensial wisata alam yang diinventarisasi memiliki kategori tinggi dikarenakan memiliki skor yang berada antara 982-1260. Obyek potensial wisata alam yang memiliki skor tertinggi ialah air terjun batu dinding 1 dan 2 serta air selancar yang memiliki nilai 1050, sedangkan untuk obyek potensial alam yang memiliki skor terendah ialah air terjun batang kapas $\pm 150 \mathrm{~m}$ yang berada di desa Lubuk Bigau dengan nilai 990.
Nilai dari kelima obyek potensial yang ada di dua desa tersebut berpeluang untuk dikembangkan karena termasuk kategori tinggi. Hal ini juga diperkuat dari hasil penelitian pengembangan obyek wisata di Suaka Margasatwa Bukit Batu yang berada di Kabupaten Bengkalis dengan nilai 1170. (Haris, 2017).

\section{Unsur Aksebilitas}

Interval skor yang didapat dari unsur aksebilitas dapat dilihat dari tabel berikut ini:

Tabel 4. Interval Skor Unsur Aksebilitas

$\begin{array}{llllllll}\text { No. } & \text { Kategori } & \text { Interval } & \begin{array}{c}\text { Air Terjun } \\ \text { Batang } \\ \text { Kapas 150 } \\ \mathbf{m}\end{array} & \begin{array}{c}\text { Air Terjun } \\ \text { Batang } \\ \text { Kapas 50 } \\ \mathbf{m}\end{array} & \begin{array}{c}\text { Air Terjun } \\ \text { Batu } \\ \text { Dinding 1 1 }\end{array} & \begin{array}{c}\text { Air Terjun } \\ \text { Batu } \\ \text { Dinding 2 }\end{array} & \begin{array}{c}\text { Air } \\ \text { Selancar }\end{array} \\ 1 & \text { Tinggi } & 517-700 & \text { Rendah } & \text { Rendah } & \text { Sedang } & \text { Sedang } & \text { Sedang } \\ 2 & \text { Sedang } & 334-516 & 175 & 225 & 375 & 375 & 375 \\ 3 & \text { Rendah } & 150-333 & 175 & & & \end{array}$

Sumber: Hasil Olahan Data Primer 2017

Dari tabel diatas didapat bahwa dari 5 obyek potensial wisata alam yang diinventarisasi memiliki kategori yang beragam, obyek yang memiliki kategori sedang ialah obyek potensial wisata alam yang terdapat di desa Tanjung Belit yaitu air terjun batu dinding 1 dan 2 dan air selancar dengan skor 375 , 
sedangkan yang memiliki kategori rendah ialah air terjun batang kapas \pm 150 m dengan skor 175. Untuk nilai dengan skor rendah memiliki aksebilitas yang belum bisa menunjang potensi obyek wisata alam, skor rendah pada unsur Aksebilitas umumnya terjadi karena jarak tempuh yang jauh dan juga kondisi jalan yang belum diaspal (jalan tanah/pengerasan) atau hanya sebagian yang diaspal. Untuk nilai dengan skor sedang biasanya memiliki akses yang cukup singkat dan juga kondisi jalan yang sudah diaspal.
Kondisi Aksebilitas yang beragam pada kedua desa ini membuat obyek potensial pada kedua desa cukup identik dengan penelitian di Suaka Margasatwa Bukit Batu yang memiliki nilai 400, nilai tersebut masuk dalam kategori sedang (Haris, 2017).

\section{Unsur Kondisi Lingkungan}

Interval skor yang didapat dari unsur kondisi lingkungan dapat dilihat dari tabel berikut ini:

\section{Tabel 5. Interval Skor Unsur Kondisi Lingkungan}

\begin{tabular}{|c|c|c|c|c|c|c|c|}
\hline No. & Kategori & Interval & $\begin{array}{c}\text { Air Terjun } \\
\text { Batang } \\
\text { Kapas } 150 \\
\text { m }\end{array}$ & $\begin{array}{c}\text { Air Terjun } \\
\text { Batang } \\
\text { Kapas } 50 \mathrm{~m}\end{array}$ & $\begin{array}{c}\text { Air Terjun } \\
\text { Batu } \\
\text { Dinding } 1\end{array}$ & $\begin{array}{c}\text { Air Terjun } \\
\text { Batu } \\
\text { Dinding } 2\end{array}$ & Air Selancar \\
\hline 1 & $\begin{array}{l}\text { Tinggi } \\
\text { Sedang }\end{array}$ & $\begin{array}{l}236-300 \\
168-235\end{array}$ & $\begin{array}{c}\text { Sedang } \\
175\end{array}$ & $\begin{array}{c}\text { Sedang } \\
175\end{array}$ & $\begin{array}{c}\text { Sedang } \\
225\end{array}$ & $\begin{array}{c}\text { Sedang } \\
225\end{array}$ & $\begin{array}{c}\text { Sedang } \\
225\end{array}$ \\
\hline
\end{tabular}

Sumber: Hasil Olahan Data Primer 2017

Dari tabel diatas didapati bahwa 5 obyek potensial wisata alam termasuk dalam kategori sedang, dengan nilai obyek potensial yang berada di desa Lubuk Bigau memiliki skor 175 dan obyek potensial wisata alam yang berada di desa Tanjung belit memiliki skor 225. Untuk kondisi lingkungan, umumnya berada dalam posisi sedang yang mana unsur kondisi lingkungan ini memuat tentang informasi tata ruang dan status lahan dari obyek wisata alam.
Dari lima (5) obyek wisata alam, hanya obyek wisata alam yang ada di Desa Lubuk Bigau yang belum memiliki tata ruang wilayah, sedangkan yang ada di Desa Tanjung Belit masih dalam proses penyusunan. Untuk status lahan 5 obyek wisata alam tersebut masuk kedalam hutan negara.

Penelitian ini mendapatkan kategori sedang, ketika dibandingkan dengan penelitian di Suaka Margasatwa Bukit Batu yang memiliki kategori tinggi 
dengan nilai 800 (Haris, 2017), hal ini identik dikarenakan pada penelitian di Suaka Margasatwa Bukit Batu sub unsur yang digunakan berjumlah 6 sub unsur yaitu tata ruang wilayah obyek, status lahan, mata pencarian penduduk, pendidikan, sumber daya alam, dan tanggapan masyarakat terhadap pengembangan obyek wisata alam

\section{Tabel 6. Interval Skor Unsur Akomodasi}

\begin{tabular}{|c|c|c|c|c|c|c|c|}
\hline No. & Kategori & Interval & $\begin{array}{c}\text { Air Terjun } \\
\text { Batang Kapas } \\
150 \mathrm{~m}\end{array}$ & $\begin{array}{l}\text { Air Terjun } \\
\text { Batang } \\
\text { Kapas } 50 \mathrm{~m}\end{array}$ & $\begin{array}{l}\text { Air Terjun } \\
\text { Batu } \\
\text { Dinding } 1\end{array}$ & $\begin{array}{l}\text { Air Terjun } \\
\text { Batu } \\
\text { Dinding } 2\end{array}$ & Air Selancar \\
\hline 1 & Tinggi & $142-180$ & Bondrh & & andol & & \\
\hline 2 & Sedang & $101-141$ & go & ge & tentili & & \\
\hline 3 & Rendah & $60-100$ & & & 60 & 60 & 60 \\
\hline
\end{tabular}

Sumber: Hasil Olahan Data Primer 2017

Dari tabel diatas didapati bahwa semua obyek potensial yang telah di inventararisasi mendapat skor 60 , hal ini dikarenakan akomodasi yang terdapat di dua desa, dimana obyek potensial berada belum memiliki unsur-unsur yang memadai dikarenakan tidak memiliki penginapan, sedangkan pengunjung yang ingin menginap di dua desa tersebut harus menginap di rumahrumah warga. Kondisi dari rumah warga yang ada di dua desa tersebut sudah terbuat dari batu bata dan telah memiliki kamar mandi di setiap rumah.

Jika dibandingkan dengan hasil penelitian di Suaka Margasatwa Bukit sedangkan pada penelitian ini hanya digunakan 2 sub unsur yaitu tata ruang wilayah obyek dan status lahan.

\section{Unsur Akomodasi}

Interval skor yang didapat dari unsur akomodasi dapat dilihat dari tabel berikut ini: 
Tabel 7. Interval Skor Unsur Sarana dan Prasarana

\begin{tabular}{|c|c|c|c|c|c|c|c|}
\hline \multirow[t]{2}{*}{ No. } & Kategori & Interval & $\begin{array}{c}\text { Air Terjun } \\
\text { Batang Kapas }\end{array}$ & $\begin{array}{c}\text { Air Terjun } \\
\text { Batang Kapas }\end{array}$ & $\begin{array}{c}\text { Air Terjun } \\
\text { Batu }\end{array}$ & $\begin{array}{c}\text { Air Terjun } \\
\text { Batu }\end{array}$ & $\begin{array}{c}\text { Air } \\
\text { Selancar }\end{array}$ \\
\hline & & & $150 \mathrm{~m}$ & $50 \mathrm{~m}$ & Dinding 1 & Dinding 2 & \\
\hline 1 & Tinggi & $142-180$ & Rendah & Rendah & Sedang & Sedang & Sedang \\
\hline $\begin{array}{l}2 \\
3\end{array}$ & $\begin{array}{l}\text { Sedang } \\
\text { Rendah }\end{array}$ & $60-100$ & 90 & 90 & 120 & 120 & 120 \\
\hline
\end{tabular}

Sumber: Hasil Olahan Data Primer 2017

Dari tabel diatas didapati bahwa dua desa ini hanya memiliki warung atau obyek potensial wisata alam yang memiliki unsur prasarana tertinggi yaitu obyek potensial wisata alam yang berada di desa Tanjung Belit dengan kategori sedang yang memiliki skor 120 dan yang berada di desa Lubuk Bigau memiliki kategori rendah dengan skor 90. Pada unsur sarana dan prasarana di Desa Lubuk Bigau belum memiliki puskesmas dan juga untuk komunikasi hanya ada pada titik tertentu serta untuk listrik hanya beroperasi dari jam 19.00 wib sampai jam 22.00 wib, sedangkan untuk Desa Tanjung Belit sudah memiliki puskesmas dan juga telah memiliki jaringan listrik yang beroperasi selama 24 jam. Untuk sarana penunjang pada kios yang menjual kebutuhan seharihari.

Jika dibandingkan dengan hasil penelitian di Suaka Margasatwa Bukit Batu, unsur sarana dan prasarana pada penelitian ini belum mendukung dikarenakan unsur akomodasi di Suaka Margasatwa Bukit Batu telah masuk dalam kategori tinggi dengan nilai 240 (Haris, 2017).

\section{Unsur Air Bersih}

Interval skor yang didapat dari unsur air bersih dapat dilihat dari tabel berikut ini:

\section{Tabel 8. Interval Skor Unsur Air Bersih}

\begin{tabular}{|c|c|c|c|c|c|c|c|}
\hline No. & Kategori & Interval & $\begin{array}{l}\text { Air } \\
\text { Terjun } \\
\text { Batang } \\
\text { Kapas } \\
150 \mathrm{~m}\end{array}$ & $\begin{array}{c}\text { Air Terjun } \\
\text { Batang } \\
\text { Kapas } 50 \mathrm{~m}\end{array}$ & $\begin{array}{c}\text { Air } \\
\text { Terjun } \\
\text { Batu } \\
\text { Dinding 1 }\end{array}$ & $\begin{array}{c}\text { Air } \\
\text { Terjun } \\
\text { Batu } \\
\text { Dinding } 2\end{array}$ & $\begin{array}{c}\text { Air } \\
\text { Selancar }\end{array}$ \\
\hline 1 & Tinggi & $702-900$ & Tinggi & Tinggi & Tinggi & Tinggi & Tinggi \\
\hline 2 & Sedang & $501-701$ & 900 & 900 & 870 & 870 & 870 \\
\hline
\end{tabular}


3 Rendah 300-500

Sumber: Hasil Olahan Data Primer 2017

Dari tabel diatas dapat dilihat bahwa semua obyek potensial wisata alam yang diinventarisasi memiliki kategori tinggi, dengan nilai tertinggi 900 yang terdapat pada obyek wisata alam di desa Lubuk bigau dan nilai 870 terdapat pada obyek wisata alam di desa Tanjung Belit. Untuk unsur air bersih, obyek wisata di Desa Lubuk Bigau memiliki skor yang paling tinggi dikarenakan sumber air bersih yang terdapat pada obyek wisata tersebut bisa langsung dikonsumsi, sedangkan pada obyek wisata di Desa Tanjung Belit masih harus dilakukan perlakuan agar air yang diambil dari sumber air bersih dapat dikonsumsi. Hal ini terjadi dikarenakan pada sumber air bersih di Desa Tanjung Belit sudah banyak tercemar oleh pengunjung yang tidak bertanggung jawab terhadap sampah yang dibawanya ketika berkunjung ke obyek wisata tersebut.

Unsur air bersih pada penelitian ini tergolong tinggi dengan skor 870 dan 900, sedangkan pada penelitian di Suaka Marga Satwa Bukit Batu Kabupaten Bengkalis memiliki nilai 810 . Nilai yang diperoleh dari penelitian ini dan penelitian yang dilakukan di Suaka
Margasatwa Bukit Batu dapat dikatakan identik larena masih berada di kategori tinggi (Haris, 2017).

\section{Peta Obyek Potensial Wisata Alam}

Setelah melakukan observasi dan penilaian menggunakan tally sheet analisis ODTWA pada obyek potensial wisata alam, maka selanjutnya dilakukan pemetaan terhadap obyek wisata alam yang telah dilakukan dengan menggunakan alat rekam titik koordinat dan track perjalanan yang berupa GPS.

Sebelum melakukan overlay titik koordinat dan track dari GPS, terlebih dahulu peneliti melakukan overlay terhadap peta-peta dari data sekunder yang berupa peta tutupan lahan, peta aliran sungai, peta jaringan jalan, dan juga peta administrasi. Proses overlay peta-peta dari data sekunder dapat dilihat pada gambar 1. Dari gambar 1 dapat dilihat bahwa tutupan lahan pada penelitian ini masih tergolong hutan primer yang ditandai dengan warna hijau.

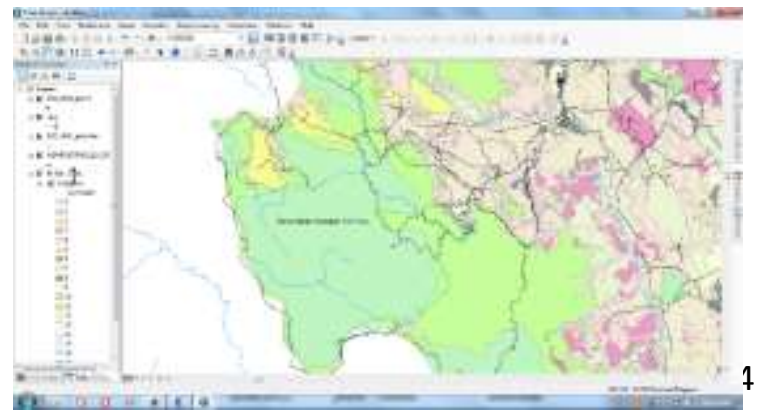




\section{Gambar 1 Proses Overlay Peta-Peta Dari} Hasil Dyerl's apenta-peta dari data sekunder yang menjadi Peta Rupa Bumi Indonesia (RBI) Kecamatan Kampar Kiri Hulu yang nantinya di-overlay dengan track dan titik koordinat yang dapat dilihat pada lampiran 2 yaitu peta dengan judul Peta Lokasi Penelitian.

Setelah peta-peta dari data sekunder di-overlay, maka selanjutnya peneliti melakukan overlay track dan titik koordinat yang telah diambil di lapangan ke dalam hasil overlay peta-peta dari data sekunder. Proses overlay tersebut dapat dilihat pada gambar 2 berikut.

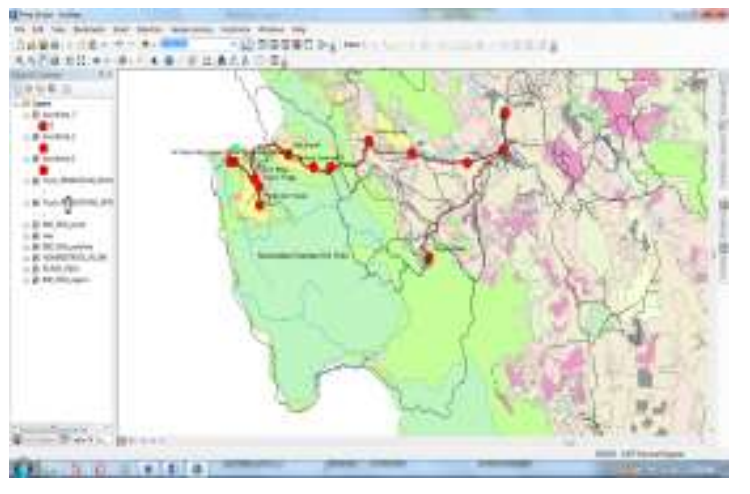

\section{Gambar 2. Proses overlay titik Koordinat dan track Penelitian}

Dari hasil overlay track dan titik koordinat yang telah diambil dilapangan, maka dapat dilihat bahwa 2 obyek wisata alam yang ada di desa Lubuk Bigau dikategorikan menjadi wisata alam minat khusus dikarenakan kondisi medan dan juga akses untuk mengunjungi obyek tersebut sulit untuk dilalui dengan kendaraan konvensional yang biasa ditemukan di jalanan kota dan juga untuk sampai ke lokasi obyek wisata dibutuhkan waktu dengan berjalan kaki sekitar 3 jam. Sedangkan untuk 3 obyek wisata alam yang ada di desa Tanjung Belit dapat di kategorikan menjadi wisata alam keluarga dikarenakan kondisi obyek wisata yang mudah diakses dengan kendaraan konvensional dan juga memiliki sarana dan prasarana penunjang yang cukup baik bagi pengunjung dan juga waktu tempuh dari Desa Tanjung Belit ke obyek wisata hanya membutuhkan waktu 30 menit, hal ini jauh berbeda dengan kondisi di Desa Lubuk Bigau.

\section{Sarana dan Prasarana}

Setelah melakukan survey dan observasi di lapangan, maka peneliti dapat menjelaskan sarana dan prasarana yang terdapat di 2 desa yang ada di Kecamatan Kampar Kiri Hulu. Adapun sarana dan prasarana yang disurvey dan diteliti dapat dilihat pada tabel 10 berikut. 


\section{Tabel 9. Kondisi Sarana dan Prasarana Obyek Wisata Alam}

\begin{tabular}{cl} 
No. & \multicolumn{1}{c}{ Sarana dan } \\
& Kondisi jalan \\
1 & $\begin{array}{l}\text { a. Aspal } \\
\text { b. Pengerasan }\end{array}$ \\
2 & C. Tanah/setapak \\
2 & Puskesmas \\
3 & $\begin{array}{l}\text { Penginapan } \\
\text { Sarana Umum }\end{array}$ \\
4 & a. Pasar \\
b. Bank \\
C. Tempat Ibadah
\end{tabular}

Sumber: Hasil Olahan Data Primer 2017

Dari tabel diatas dapat dilihat perbandingan antara sarana dan prasarana pada 2 desa yang memiliki obyek potensial wisata alam. Dari tabel 10 diatas dapat dilihat bahwa dari kondisi jalan desa Tanjung Belit memiliki jarak tempuh yang lebih pendek menuju ke pusat kota yaitu sepanjang $30.833 \mathrm{~m}$ dengan kondisi jalan $29.561 \mathrm{~m}$ merupakan jalan aspal dan $1.272 \mathrm{~m}$ jalan setapak dari Desa Tanjung Belit menuju obyek potensial wisata alam, sedangkan dari desa Lubuk Bigau ke menuju ke pusat kota sepanjang 71.857 $\mathrm{m}$ dengan kondisi jalan aspal sepanjang $40.637 \mathrm{~m}$, kondisi jalan berupa pengerasan sepanjang $25.131 \mathrm{~m}$ serta dari desa Lubuk Bigau menuju obyek potensial yaitu jalan setapak sepanjang $6.089 \mathrm{~m}$.

Selain perbedaan jarak dan kondisi jalan, jumlah puskesmas juga

$\begin{array}{cc}\text { Tanjung Belit } & \text { Desa } \\ 29.561 \mathrm{~m} & \text { Lubuk Bigau } \\ 0 & 40.637 \mathrm{~m} \\ 1.272 \mathrm{~m} & 25.131 \mathrm{~m} \\ 1 & 6.089 \mathrm{~m} \\ 15-30 \mathrm{kamar} & 0 \\ 0 & <15 \mathrm{kamar} \\ 0 & 0 \\ 2-4 \text { unit (Masjid) } & 1-2 \text { Unit (Masjid) }\end{array}$

berpengaruh terhadap penilaian suatu obyek potensial wisata alam yang mana pada Desa Tanjung Belit terdapat 1 unit puskesmas sedangkan pada Desa Lubuk Bigau tidak ditemukan puskesmas. Untuk penginapan Desa Tanjung Belit lebih banyak menyediakan jumlah kamr dibandingkan dengan Desa Lubuk Bigau yang mana kamar-kamar yang disediakan disini merupakan kamar-kamar yang berada dirumah penduduk yang bisa dipakai pengunjung untuk menginap.

Untuk sarana umum seperti pasar dan bank kedua desa ini tidak memilikinya, akan tetapi untuk tempat ibadah Desa Tanjung belit memiliki 3-5 unit masjid dan Desa Lubuk Bigau memiliki 1-2 unit masjid. Perbedaan jarak tempuh, kondisi jalan, serta sarana dan prasarana lain menjadi kendala bagi desa Lubuk Bigau untuk dijadikan obyek 
wisata alam keluarga, dikarenakan dari Desa Lubuk Bigau akan tetapi obyek wisata yang ada di desa Lubuk Bigau dapat menjadi obyek wisata minat khusus. Obyek wisata minat khusus merupakan obyek wisata yang diperuntukkan bagi individu maupun kelompok yang memiliki minat yang tidak semua orang bisa melakukannya, seperti pendakian gunung, pemanjatan tebing, pengarungan jeram sungai, dan lain-lain.Peta kondisi sarana dan prasarana 2 desa yang memiliki obyek berpotensi wisata alam dapat dilihat pada lampiran 3. Sedangkan peta tentang sebaran obyek potensial wisata alam dapat dilihat pada lampiran 4 dan 5.

\section{KESIMPULAN DAN SARAN}

\section{Kesimpulan}

Kesimpulan dari penelitian ini adalah sebagai berikut:

1. Terdapat 5 obyek wisata alam yang potensial yaitu air terjun batu dinding 1 dan 2 serta air seluncur yang terdapat di desa Tanjung Belit dan air terjun batang kapas $50 \mathrm{~m}$ dan $150 \mathrm{~m}$ yang terdapat di desa Lubuk Bigau, Kecamatan Kampar Kiri Hulu.

2. Penyajian peta lokasi sebaran obyek potensial wisata alam yang terdapat di desa Tanjung Belit dan desa Lubuk Bigau Kecamatan Kampar Kiri Hulu memuat informasi sarana dan prasarana berupa jalan menuju obyek potensial wisata alam dan tutupan lahan pada obyek potensial wisata alam serta kondisi unsur-unsur yang dinilai pada obyek potensial wisata alam yaitu unsur daya tarik wisata alam, unsur aksebilitas, unsur kondisi lingkungan, unsur akomodasi, unsur sarana dan prasarana, dan unsur air bersih.

\section{Saran}

Saran yang dapat peneliti berikan terkait penelitian ini ialah:

1. Dalam pembangunan sarana dan prasarana yang dilakukan pemerintah sebaiknya juga melihat unsur lingkungan serta keamanan bagi masyarakat yang menggunakan sarana dan prasarana tersebut.

2. Sebaiknya pembangunan sarana dan prasarana dilakukan dengan melibatkan unsur dari masyarakat yang berada di sekitar obyek potensial wisata alam agar pembangunan sarana dan prasarana dapat berguna secara maksimal bagi masyarakat. 


\section{DAFTAR PUSTAKA}

[BPS] Badan Pusat Statistik Kabupaten Kampar. 2016. Kecamatan Kampar Kiri Hulu Dalam Angka 2016. Bangkinang.

[PHKA] Perlindungan Hutan dan Konservasi Alam. 2003 (a). Pedoman Analisis Daerah Operasi Obyek dan Daya Tarik Wisata Alam (ADO -ODTWA). Direktorat Jenderal Perlindungan Hutan dan Konservasi Alam. Bogor.

[PHPA] Perlindungan Hutan dan Pelestarian Alam. 1996. Pola Pengelolaan Kawasan Suaka Alam, Kawasan Pelestarian Alam, Taman Wisata Alam dan Hutan Lindung. Direktorat Jenderal Perlindungan Hutan dan Pelestarian Alam. Bogor.

Cristanto, F. dan Susanto. 2013. Pemetaan Sarana dan Prasarana Obyek Pariwisata di Kabupaten Semarang Jawa Tengah Menggunakan Sistem Informasi Geografis. Jurnal Transformatika Vol. 10, No 2. Semarang.

Departemen Kehutanan. 1989. Kamus Kehutanan Ed ke-1. Departemen Kehutanan Republik Indonesia. Jakarta.

Departemen Kehutanan. 1990. UndangUndang Republik Indonesia Nomor 9 Tahun 1990 Tentang Kepariwisataan. Departemen Kehutanan Republik Indonesia. Jakarta.
Departemen Kehutanan. 1990. UndangUndang Republik Indonesia Nomor 5 Tahun 1990 Tentang Konservasi Sumberdaya Alam Hayati dan Ekosistemnya. Departemen Kehutanan Republik Indonesia. Jakarta.

Hakim, L. 2004. Dasar- Dasar Ekowisata. Bayumedia. Malang.

Hamid, E. A. C. 1996. Dasar-Dasar Pengetahuan

Pariwisata.

Yayasan Bhakti Membangun. Jakarta.

Haris, Muaz. 2017. Pengembangan Ekowisata Di Suaka Margasatwa Bukit Batu Kecamatan Bukit Batu Kabupaten Bengkalis Provinsi Riau [Tesis]. Bogor: Sekolah Pascasarjana Institut Pertanian Bogor.

Kementerian Kebudayaan dan Pariwisata Republik Indonesia. 2003. Ekowisata Prinsip dan Kriteria. Kementerian Kebudayaan dan Pariwisata Republik Indonesia dan Indecon. Jakarta.

Kementerian Lingkungan Hidup dan Kehutanan. 2015. Statistik Kementrian Lingkungan Hidup dan Kehutanan 2014. Kementrian Lingkungan Hidup dan Kehutanan. Jakarta.

Ko, R. K .T. 2001. Obyek Wisata Alam: Pedoman Identifikasi, Pengembangan, Pengelolaan, Pemeliharaan dan Pemasaran. Yayasan Buena Vista. Bogor.

Kodhyat, H. 1996. Sejarah Pariwisata dan Perkembangannya di 
Indonesia. PT. Gramedia

Widiasarana Indonesia. Jakarta.

Marpaung, H. 2002. Pengetahuan

Kepariwisataan Ed Revisi.

Alfabeta. Bandung.

Prahasta, Eddy. 2001. Konsep-konsep

Dasar Sistem Informasi

Geografis. Informatika. Bandung.

Raharjana, Destha T. 2012. Membangun Pariwisata Bersama Rakyat: Kajian Partisipasi Lokal Dalam Membangun Desa Wisata di Dieng Plateau. Kawistara. Yogyakarta.

Sinaga, Maruli. 1999. Pengetahuan Peta. Yogyakarta: UGM Press.

Soekadijo, R. G. 2000. Anatomi Pariwisata: Memahami Pariwisata sebagai "Systemic Linkage". PT Gramedia Pustaka Utama. Jakarta.

Sudarto, G. 1999. Ekowisata: Wahana Pelestarian Alam,

Pengembangan Ekonomi

Berkelanjutan, dan Pemberdayaan Masyarakat. Yayasan Kalpataru Bahari. Bekasi.

Suwantoro, G. 1997. Dasar-Dasar

Pariwisata. ANDI. Yogyakarta. 